\title{
PENATAAN KAWASAN SEGITIGA JATINEGARA SEBAGAI IKON WISATA JAKARTA TIMUR
}

\author{
James Jonathan ${ }^{1)}$, Liong Ju Tjung ${ }^{2)}$, Bambang Delianto ${ }^{3)}$ \\ 1) Program Studi S1 PWK, Fakultas Teknik, Universitas Tarumanagara, jamesjonathan52@gmail.com \\ 2) Program Studi S1 PWK, Fakultas Teknik, Universitas Tarumanagara, liongjutjung@gmail.com \\ 3) Program Studi S1 PWK, Fakultas Teknik, Universitas Tarumanagara, deli.bambang@gmail.com
}

\begin{abstract}
Abstrak
Kawasan Segitiga Jatinegara ini terletak di Kota Administratif Jakarta Timur yang dikenal memiliki nuansa kental sejarah dan perdagangan sebagai urat nadi ekonomi masyarakat sejak era kolonial di Indonesia. Sebagai pusat perdagangan dan jasa, Segitiga Jatinegara ini merupakan kawasan pembelanjaan yang unik, karena adanya pusat perdagangan tradisional atau pasar Regional Jatinegara (dahulu dikenal sebagai Pasar Meester), dan Pasar Batu Akik dan Permata Rawa Bening yang berlokasi di seberang Stasiun Jatinegara. Pasar Batu Akik sedemikian unik karena pasar ini menjual berbagai macam batu akik, permata dan barang-barang pusaka tidak hanya dikenal di Jakarta, tetapi juga dikenal hingga Mancanegara. Pada Perda no 1 Tahun 2014 tentang Rencana Tata Ruang Detail Kecamatan Jatinegara dikatakan bahwa terdapat pengembangan kawasan pariwisata dengan pengembangan dan perbaikan fungsi kawasan wisata perkotaan dan pengembangan Pusat Kebudayaan Betawi di Kawasan Jatinegara Namun, masih terdapat beberapa permasalahan yang terjadi di kawasan Segitiga Jatinegara seperti terdapat PKL yang berada di atas trotoar yang mengakibatikan ketidaknyaman para pejalan kaki serta menyebabkan matinya beberapa pertokoan dan pusat perbelanjaan di kawasan ini, masih kurangnya ruang terbuka hijau, banyak bangunan tua yang tidak terawat yang memiliki nilai sejarah, dan kurangnya lahan parkir yang mengakibatkan parkir liar di pinggir jalan. Maka itu, akan dilakukan beberapa penataan pada Kawasan Segitiga Jatinegara seperti meningkatkan fungsi kawasan, merevitalisasi bangunan-bangunan tua, menambah lahan parkir, menambah furniture street kawasan dan meningkatkan aksesibilitas kawasan, hal ini dilakukan agar menjadi kawasan dengan konsep Shopping Street yang memiliki ciri Khas dengan bangunan konservasi sebagai Ikon Wisata Jakarta Timur sebagai hasil dari penataan ini.
\end{abstract}

Kata Kunci: Kawasan Segitiga Jatinegara; Wisata Belanja; Wisata Sejarah; Wisata Kota

\begin{abstract}
The Jatinegara Triangle Region is located in the Administrative City of East Jakarta, which is known to have a thick nuance of history and trade as the economic lifeblood of society since the colonial era in Indonesia. As the center of trade and services, the Jatinegara Triangle is a unique shopping area, because of the traditional trade center or Jatinegara Regional Market (formerly known as Pasar Meester), and Agate Stone Market and Permata Rawa Bening located opposite Jatinegara Station. Agate Stone Market is so unique because this market sells various kinds of Agate Stone, gems and heirlooms not only known in Jakarta, but also known to foreign countries. In Perda No. 1 of 2014 concerning Detail Spatial Planning in Jatinegara Subdistrict, it is said that there is a tourism area development with the development and improvement of urban tourism functions and the development of the Betawi Cultural Center in Jatinegara Region. However, there are still some problems in the Jatinegara Triangle area such as street vendors which is on the sidewalk which results in the inconvenience of pedestrians and causes the death of several shops and shopping centers in the region, still lack of green open space, many old, untreated buildings that have historical value, and lack of parking
\end{abstract}


spaces resulting in illegal parking on the edge Street. Therefore, some arrangements will be made in the Jatinegara Triangle Area such as improving the function of the area, revitalizing old buildings, adding parking lots, adding regional street furniture and increasing regional accessibility, this is done to become an area with the concept of Shopping Street with special characteristics conservation building as East Jakarta Tourism Icon as a result of this arrangement.

Keywords: City Tourism; Historical Tourism; Jatinegara Triangle Area; Shopping Tourism

\section{PENDAHULUAN}

Kawasan Segitiga Jatinegara merupakan salah satu Kawasan di Kotamadya Jakarta Timur yang berada di Kecamatan Jatinegara Kelurahan Rawa Bunga dan Balimester. dikenal memiliki nuasa kental sejarah selain dari perdagangannya, adapun pada saat era kolonial merupakan urat nadi ekonomi masyarakat di Indonesia. Maka itu, Kawasan Segitiga Jatinegara termasuk dari kawasan strategis ekonomi pusat DKI Jakarta. Hal ini dikarenakan letaknya yang strategis membuat kawasan ini menjadi kawasan yang memiliki nilai ekonomis yang tinggi.

Kawasan Segitiga Jatinegara memiliki beberapa kunikan seperti terdapat beberapa bangunan-bagunan bersejarah yang memiliki ciri khas, dan juga merupakan salah satu pusat pedagangan di Jakarta Timur, dari kedua hal ini bisa menjadikan Kawasan Segitiga Jatinegara ini menjadi factor yang tujuan wisata yang berciri khas. Selain itu, adapun penataan Kawasan Jatinegara sebagai Kawasan unggulan tertib kota. Kawasan Unggulan Tertib Kota merupakan salah satu efek dari Perda No 1 Tahun 2014 mengenai perwujudan pengembangan kawasan perdagangan dan jasa melalui perbaikan prasarana PKL serta peningkatan prasarana perdagangan disertai penataan prasarana pejalan kaki dan penataan transportasi. Adapun perwujudan dari pengembangan kawasan pariwisata di daerah Kawasan Segitiga Jatinegara dengan melakukan pengembangan dan perbaikan

Maka itu, penulis tertarik untuk melakukan penataan Jatinegara sebagai Ikon Wisata Jakarta Timur dengan beberapa pendukung dari terciptanya sebuah destinasi wisata yang memiliki ciri khas di Kawasan ini.

\section{KAJIAN LITERATUR}

\section{Penataan}

Berdasarkan pasal 2 Undang-Undang No. 26 th 2007 ditegaskan bahwa penataan ruang diselenggarakan berdasarkan asas, yaitu sebagai berikut:

a. Keterpaduan

Keterpaduan adalah bahwa penataan ruang diselenggarakan dengan mengintegrasikan berbagai kepentingan yang bersifat lintas sektor, lintas wilayah, dan lintas pemangku kepentingan. Pemangku kepentingan antara lain, adalah pemerintah, pemerintah daerah, dan masyarakat.

b. Keserasian, keselarasan, dan keseimbangan

Keserasian, keselarasan, dan keseimbangan adalah bahwa penataan ruang diselenggarakan dengan mewujudkan keserasian antara struktur ruang dan pola ruang, keselarasan antara kehidupan manusia dengan lingkungannya, keseimbangan pertumbuhan dan perkembangan antar daerah serta antara kawasan perkotaan dan kawasan perdesaan. 
c. Keberlanjutan

Keberlanjutan adalah bahwa penataan ruang diselenggarakan dengan menjamin kelestarian dan kelangsungan daya dukung dan daya tamping lingkungan dengan memperhatikan kepentingan generasi mendatang.

d. Keberdayagunaan dan keberhasilgunaan

Keberdayagunaan dan keberhasilgunaan adalah bahwa penataan ruang diselenggarakan dengan mengoptimalkan manfaat ruang dan sumber daya yang terkandung di dalamnya serta menjamin terwujudnya tata ruang yang berkualitas

e. Keterbukaan

Keterbukaan adalah bahwa penataan ruang diselenggarakan dengan memberikan akses yang seluas-luasnya kepada masyarakat untuk mendapatkan informasi yang berkaitan dengan penataan ruang.

f. Kebersamaan dan kemitraan.

Kebersamaan dan kemitraan adalah bahwa penataan ruang diselenggarakan dengan melibatkan seluruh pemangku kepentingan.

g. Perlindungan kepentingan umum.

Perlindungan kepentingan umum adalah bahwa penataan ruang diselenggarakan dengan mengutamakan kepentingan masyarakat.

h. Kepastian hukum dan keadilan.

Kepastian hukum dan keadilan adalah bahwa penataan ruang diselenggarakan dengan berlandaskan hukum/ketentuan peraturan perundang-undangan dan bahwa penataan ruang dilaksanakan dengan mempertimbangkan rasa keadilan masyarakat serta melindungi hak dan kewajiban semua pihak secara adil dengan jaminan kepastian hukum. i. Akuntabilitas.

Akuntabilitas adalah bahwa penyelenggaraan penataan ruang dapat dipertanggungjawabkan, baik prosesnya, pembiayaannya, maupun hasilnya. Penataan ruang harus dilakukan secara berjenjang dan komplementer.

\section{Ikon Kota}

Ikon dalam pengertian umum merupakan sebuah gambar yang disederhanakan namun setiap gambar yang mewakili obyek yang direpresentaikan. Ikon Kota dapat di defenisikan sebagai bangunan bentuk yang di bangun menyerupai sesuatu yang di maksudkan untuk menyampaikan pesan atau mencerminkan identitas atau karakter masyarakat,identitas budaya, tatanan sosial, identitas keagamaan, budaya masa laluSejarah, simbol kekuasaan, kejayaan, kejayaan ekonomi,kejayaan teknologi, atau pengharapan ke masa yang akan datang.

Atau pula di maksudkan sebagai media untuk menunjukkan sebuah identitas masyarakat baik identitas ideologi, identitas manusia dan alam secara umum Icon. icon kota tersebut bisa berbentuk

a) Bangunan keagamaan seperti masjid di aceh, vihara, candi dsb.

b) Bangunan sate di surabaya

c) Bangunan tradisonal seperti rumah adat, bangunan kolonial, bangunan Ibadah kuno

d) Bangunan tugu seperti tuguh Monumen nasional di jakarta, tugu pahlawan di Surabaya, Tugu Monumen mandala pembebasan irian barat di makassar

e) Bangunan biorama seperti Biorama peristiwa G.30s PKI di lubang buaya, biorama Pahlawan di Kraton Jogjakarta

f) Lapangan seperti lapangan ikada/merdeka atau taman monas, lapangan karebosi di makssar dsb. 
g) Patung/bangunan bentuk menyerupai tokoh seperti patung jendral sudirman, patung sultan hasanuddin di Makassar, Patung jalasveva jayamahe di tanjung perak, arung palakka di watampone dsb.

h) Patung /bangunan bentuk menyerupai binatang, seperti bangunan bentuk Buaya di surabaya, kerbau di india, Naga di china dsb

i) Bangunan bentuk peralatan tempur seperti bangunan bentuk keris di Luwu Bangunan bentuk keris di Gowa dsb

j) Dan Bangunan bangunan berbentuk lainnya yang di harapkan menjadi media menyampaikan pesan pesan moral kepada masyarakat secara umum.

Adapun yang beberapa kriteria dari Kevin Lynch, (1975: 6-8) dalam bukunya "The Image of The City" sebuah Citra/ image memerlukan.

a. Identitas pada sebuah obyek atau sesuatu yang berbeda dengan yang lain

b. Struktur atau pola saling hubung antaran obyek dan pengamat

c. Obyek tersebut mempunyai makna bagi pengamatnya.

\section{Wisata Heritage}

Pada pasal 1 UU RI No. 5 Tahun 1992 tentang Benda Cagar Budaya mendefinisikan Benda Cagar Budaya sebagai berikut:

a) Benda buatan manusia, bergerak atau tidak bergerak yang berupa kesatuan atau kelompok, atau bagian-bagiannya atau sisa-sisanya, yang berumur sekurangkurangnya 50 tahun, atau mewakili masa gaya yang khas dan mewakili masa gaya sekurang-kurangnya 50 tahun, serta dianggap mempunyai nilai penting bagi sejarah, ilmu pengetahuan, dan kebudayaan.

b) Benda alam yang dianggap mempunyai nilai penting bagi sejarah, ilmu pengetahuan, dan kebudayaan.

\section{METODE}

Jenis data yang digunakan pada penelitian ini terbagi atas Data Primer dan Data Sekunder yaitu:

a) Data Primer

Data primer merupakan data yang didapatkan secara langsung dari objek penelitian.

Pengumpulan data primer yaitu sebagai berikut:

a. Kondisi fisik eksisting dari Kawasan Segitiga Jatinegara

b. Pengunaan lahan di kawasan Segitiga Jatinegara

c. Melakukan pendataan daya tarik wisata di Kawasan Segitiga Jatinegara

d. Dokumentasi dan data sejarah kawasan Segitiga Jatinegara

e. Melakukan wawancara kepada pihak subtansi berkaitan dan masyarakat terkait Kawasan Segitiga Jatinegara.

b) Data Sekunder

Data sekunder merupakan data yang didapatkan tidak langsung melalui objek penelitian namun dari berbagai sumber-sumber yang relevan seperti buku, jurnal, dokumen pemerintah, dan sumber dari internet yang dapat dipertanggungjawabkan. Data sekunder yang digunakan dalam penelitian adalah:

1. Peraturan dan kebijakan yang terkait dengan kawasan Segitiga Jatinegara

2. Data makro Kota Administrasi Jakarta Timur

3. Benchmarking.

4. Refrensi penulisan Tugas Akhir. 


\section{DISKUSI DAN HASIL}

\section{Profil Kawasan Segitiga Jatinegara}

Kawasan Segitiga Jatinegara berada di Kelurahan Balimester dan Rawa Bunga, Kecamatan Jatinegara, Kota Administrasi Jakarta Timur. Kawasan Segitiga Jatinegara ini merupakan salah satu kawasan kedua tertua di Jakarta, Kawasan ini memiliki beberapa bangungan bersejarah yang ikut menambah keunikan karakter kawasan. Bangunanbangunan konservasi tersebut memiliki gaya arsitektur kolonial, seperti Gereja Koinonia, bangunan Eks Kodim yang sekarang menjadi Museum Benjamin Sueb, komplek TNI AD Jend Urip Sumoharjo dan Bangunan Stasiun Jatinegara. Kawasan Segitiga Jatinegara ini memiliki luas sebesar 52, $61 \mathrm{Ha}$. Kawasan ini memiliki rencana pengembang kawasan strategis ekonomi pusat DKI Jakarta. Hal ini di dorong dengan karena Kawasan Segitiga Jatinegara ini merupakan salah satu urat nadi perekonomian masyarakat di Indonesia.

\section{Analisis Tapak dan Lokasi}

Tabel 1. SWOT Analisis Tapak dan Lokasi

Strength Weakness

- Memiliki fasilitas-fasilitas yang memadai

- Masih terdapat PKL yang berjualan di Trotoar sehingga menganggu para pejalan kaki

\begin{tabular}{|c|c|c|}
\hline & $\begin{array}{l}\text { Kawasan segitiga Jatinegara memiliki moda } \\
\text { transportasi yang banyak, sehingga } \\
\text { memudahkan para pengunjung untuk } \\
\text { datang ke kawasan tersebut }\end{array}$ & $\begin{array}{l}\text { - Kurangnya ruang terbuka hijau di dalam } \\
\text { Kawasan Segitiga Jatinegara }\end{array}$ \\
\hline - & $\begin{array}{l}\text { Terdapat Pedestrian yang luas yang } \\
\text { membuat nyaman para pejalan kaki } \\
\text { nyaman. }\end{array}$ & $\begin{array}{l}\text { Masih banyak bangunan-bangunan tua } \\
\text { yang tidak terawat dan terbengkalai }\end{array}$ \\
\hline - & $\begin{array}{l}\text { Terdapat beragam kebudayaan etnis di } \\
\text { Kawasan Segitiga Jatinegara }\end{array}$ & $\begin{array}{l}\text { Kurangnya fasilitas pendukung dari trotoar } \\
\text { di Kawasan Segitiga Jatinegara }\end{array}$ \\
\hline - & $\begin{array}{l}\text { Banyaknya PKL yang bisa menjadi salah satu } \\
\text { magnet perekonomian dan wisatawan }\end{array}$ & Kurangnya Lahan Parkir \\
\hline - & Memiliki fasilitas-fasilitas yang memadai & $\begin{array}{l}\text { Masih terdapat PKL yang berjualan di Trotoar } \\
\text { sehingga menganggu para pejalan kaki }\end{array}$ \\
\hline \multicolumn{2}{|c|}{ Opportunity } & Threat \\
\hline - & $\begin{array}{l}\text { Kawasan Segitga Jatinegara memiliki } \\
\text { Kawasan Stategis Ekonomi di Jakarta } \\
\text { sehingga memiliki aktivitas yang tinggi }\end{array}$ & $\begin{array}{l}\text { Adanya kemacetan di Kawasan Segitiga } \\
\text { Jatinegara yang diakibatkan angkutan } \\
\text { umum dan pedagang kaki lima }\end{array}$ \\
\hline - & $\begin{array}{l}\text { Adanya rencana pengembangan Komersial } \\
\text { dan Pusat Kebudayaan Betawi di Eks. } \\
\text { Kantor Kodim Jatinegara }\end{array}$ & $\begin{array}{l}\text { Di beberapa tempat di Kawasan Segitiga } \\
\text { Jatinegara yang memiliki bau yang } \\
\text { menyengat yang dapat mengganggu }\end{array}$ \\
\hline
\end{tabular}

- $\quad$ Adanya Stasiun KA Jatinegara yang menjadi pintu masuk bagi Jakarta dari kota-kota yang ada di Pulau Jawa.
Masih banyaknya premanisme dan vandalisme di Kawasan Segitiga Jatinegara

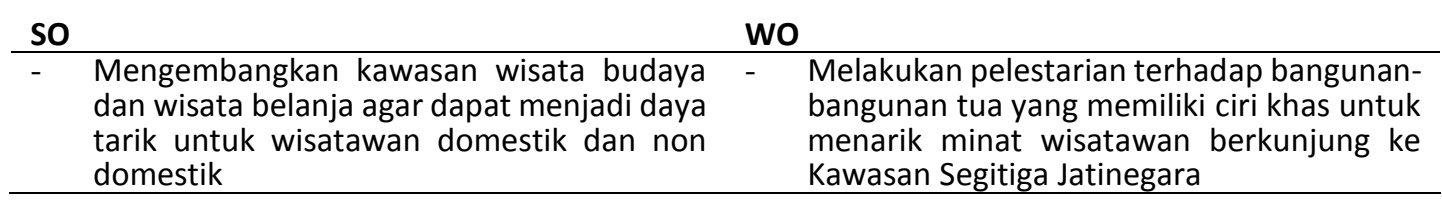




\begin{tabular}{|c|c|c|}
\hline \multirow[b]{2}{*}{ - } & \multirow[b]{2}{*}{$\begin{array}{l}\text { Menjadikan Stasiun Jatinegara menjadi } \\
\text { pusat transit dari Kawasan Segitiga } \\
\text { Jatinegara. }\end{array}$} & \\
\hline & & 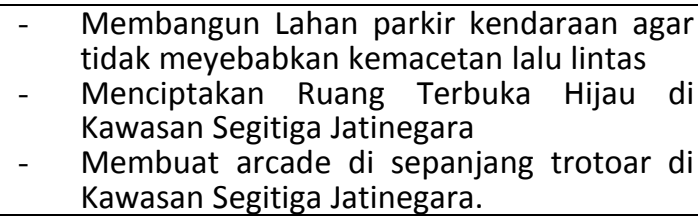 \\
\hline (1) & \multirow[t]{2}{*}{$\begin{array}{l}\text { Memberikan lahan bagi para PKL sebagai } \\
\text { salah satu magnet perkonomian di kawasan } \\
\text { setra menunjang kegiatan belanja yang } \\
\text { berkarakter unik }\end{array}$} & 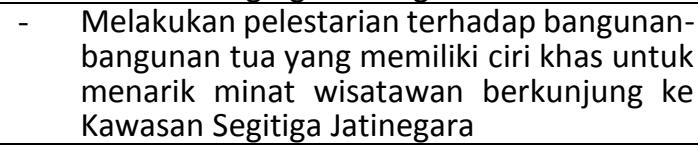 \\
\hline ST & & WT \\
\hline- & $\begin{array}{l}\text { MelakukanPeningkatan aksesibilitas Lalu- } \\
\text { lintas dengan rekayasa lalu lintas dan } \\
\text { manajemen lalu lintas }\end{array}$ & $\begin{array}{l}\text { - Memberikan papan larangan dan saran } \\
\text { disetiap tempat yang menjadi rawan } \\
\text { vandalisme dan kriminalitas }\end{array}$ \\
\hline- & $\begin{array}{l}\text { Meningkatkan keamanan bagi para } \\
\text { pengunjung wisatawan dari Kawasan } \\
\text { Segitiga Jatinegara dengan membangun } \\
\text { pos-pos keamanan di area rawan } \\
\text { kriminalitas. }\end{array}$ & $\begin{array}{l}\text { - Melakukan relokasikan pedagangan kaki } \\
\text { lima ketempat yang sesuai dengan } \\
\text { dagangan yang di jual didalam kawasan } \\
\text { maupun luar. }\end{array}$ \\
\hline
\end{tabular}

Sumber: Penulis, 2019

\section{Analisis Ikon Kota}

Beberapa tempat yang akan dijadikan sebagai Ikon Kawasan Segitiga Jatinegara.
a. Stasiun Jatinegara
b. Pasar Jatinegara
c. Gereja Koinonia
d. Gedung Eks Kodim
e. Trotoar

Dari kelima lokasi yang akan dijadikan sebagai Ikon Kota maka ada beberapa kriteria yang bisa menjadikan bangunan atau benda tersebur menjadi lkon Kota. berikut beberapa bisa dijadikan kriteria seperti Kevin Lynch, (1975: 6-8) dalam bukunya "The Image of The City" sebuah Citra/ image memerlukan.

- Identitas pada sebuah obyek atau sesuatu yang berbeda dengan yang lain

- Struktur atau pola saling hubung antaran obyek dan pengamat

- Obyek tersebut mempunyai makna bagi pengamatnya.

Selain itu, adapun Bangunan Icon atau simbol yang dengan sengaja di buat untuk menghiasi kota atau menghiasi kawasan tertentu adalah bangunan yang menyampaikan pesan moral pesan moral yang dimaksudkan dapat berupa

- Pesan dari satu generasi ke generasi lainnya

- Pesan dari satu kelompok masyarakat kepada masyarakat umum lainnya

- Atau pesan untuk menunjukkan integritas,kekuasaan dan kejayaan

- Pesan yang mempertegas eksistensi dan menunjukkan pada khalayak umum.

Jadi, kesimpulannya dari beberapa bangunan yang akan dijadikan sebagai Ikon Kota yang menggambarkan Kawasan Segitiga Jatinegara pada masa lalu maupun masa sekarang. Dengan adanya Ikon ini dapat menjadi gambaran yang baru untuk Kawasan untuk mengubah pola dan perilaku dari masyarakat yang lebih baik serta menjadikan kawasan ini memiliki ciri khas tersendiri yang bisa dijadikan sebagai daya tarik wisatawan. 


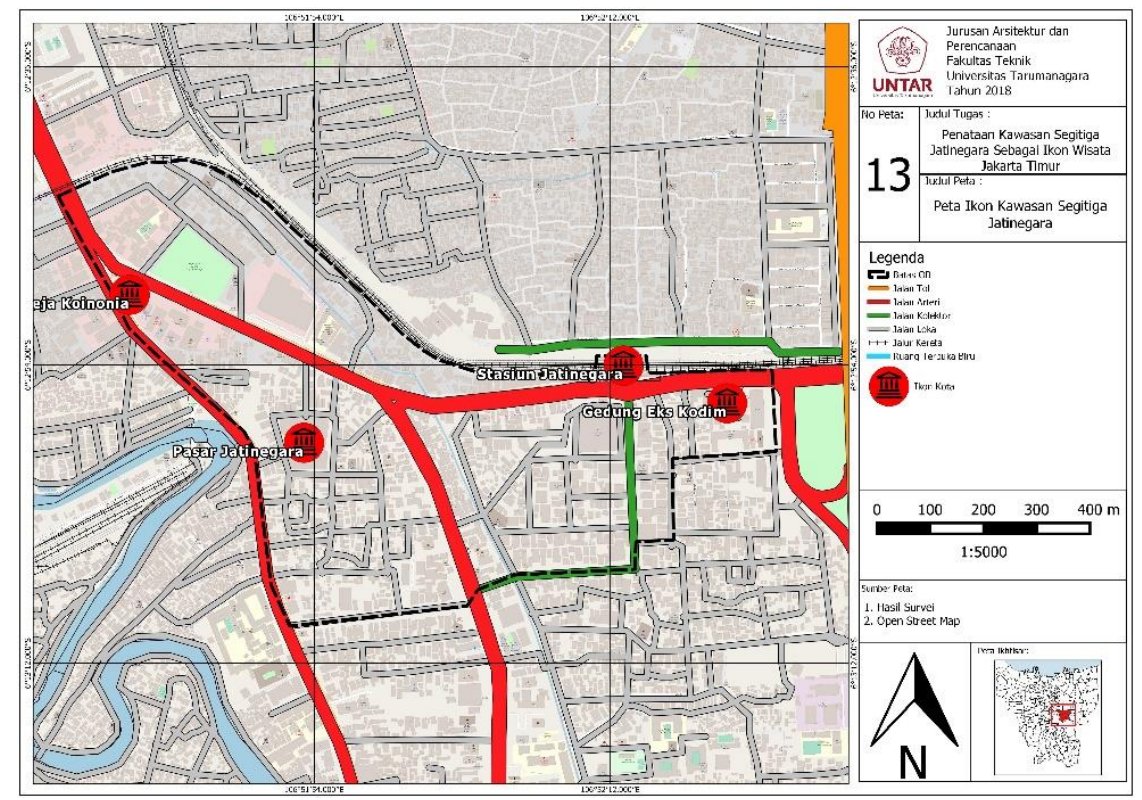

Gambar 1. Peta Ikon Kawasan Segitiga Jatinegara Sumber: Olahan Penulis, 2019

\section{Analisis Identifikasi Pemanfaatan Ruang}

Pada analisis penulis ingin melakukan pencocokan antara Hak atas tanah (eksisting), Potensi, serta Urban Design guideline yang bertujuan untuk melihat potensi yang ada pada Kawasan Segitiga Jatinegara, serta menjadikan sebagai acuan dari penataan Kawasan ini.

\section{UDGL dengan Eksisting}

Tabel 2. Hasil Overlay antara UDGL dengan Status Lahan Kawasan Segitiga Jatinegara

\begin{tabular}{|c|c|c|c|}
\hline No & Nama/Lokasi & Keterangan & Rekomendasi \\
\hline 1 & Blok B 8 & $\begin{array}{l}\text { Pada Blok B } 8 \text { pada eksisting terdapat } \\
\text { penggunaan lahan Campuran yang memiliki } \\
\text { Hak belum terdaftar. Pada UDGL Blok B } 8 \text { ini } \\
\text { dapat diubah menjadi lahan Parkir. }\end{array}$ & $\begin{array}{l}\text { Blok B } 8 \text { akan di } \\
\text { rekomendasikan } \\
\text { sebagai Wadah Parkir } \\
\text { di kawasan. Sesuai } \\
\text { UDGL }\end{array}$ \\
\hline 2 & Blok C7 & $\begin{array}{l}\text { pada Blok C } 7 \text { pada eksistingnya merupakan } \\
\text { permukiman yang memiliki Hak Belum } \\
\text { Terdaftar dan pada UDGL merupakan ruang } \\
\text { terbuka hijau, }\end{array}$ & $\begin{array}{l}\text { blok C } 7 \text { akan di Ubah } \\
\text { menjadi ruang terbuka } \\
\text { hijau merupakan salah } \\
\text { satu masalah kawasan } \\
\text { ini sesuai UDGL. }\end{array}$ \\
\hline 3 & Blok C6 & $\begin{array}{l}\text { pada Blok C } 6 \text { pada eksistingnya merupakan } \\
\text { permukiman yang memiliki Hak Belum } \\
\text { Terdaftar dan pada UDGL merupakan ruang } \\
\text { terbuka hijau, }\end{array}$ & $\begin{array}{l}\text { blok C } 6 \text { akan di Ubah } \\
\text { menjadi ruang terbuka } \\
\text { hijau merupakan salah } \\
\text { satu masalah kawasan } \\
\text { ini sesuai UDGL }\end{array}$ \\
\hline 4 & Blok C1 & $\begin{array}{l}\text { pada Blok } \mathrm{C} 1 \text { ini pada eksistingnya } \\
\text { merupakan tempat pedagang barang rumah } \\
\text { tangga yang tidak memiliki Hak lahan. } \\
\text { Sedangkan pada UDGL merupakan ruang } \\
\text { terbuka hijau. }\end{array}$ & $\begin{array}{l}\text { Blok C1 ini akan diubah } \\
\text { menjadi Ruang terbuka } \\
\text { Hijau sesuai UDGL }\end{array}$ \\
\hline
\end{tabular}


UDGL dengan Potensi

Tabel 3. Hasil Overlay antara UDGL dengan Potensi Kawasan Segitiga Jatinegara

\begin{tabular}{|c|c|c|c|}
\hline No & Lokasi & Keterangan & Rekomendasi \\
\hline 1 & $\begin{array}{l}\text { Komplek TNI } \\
\text { AD Jend Urip } \\
\text { Sumoharjo }\end{array}$ & $\begin{array}{l}\text { Komplek ini pada UDGL merupakan } \\
\text { daerah yang akan diubah menjadi } \\
\text { penggunaan lahan Komesial } \\
\text { Campuran, Namun, pada komplek } \\
\text { ini memiliki nilai sejarah bagi } \\
\text { Kawasan Segitiga Jatinegara, Karena } \\
\text { terdapat bangunan peninggalan } \\
\text { sejarah belanda yang bergaya } \\
\text { Indiche Empire didalam komplek } \\
\text { tersebut }\end{array}$ & $\begin{array}{l}\text { Komplek TNI AD Jend Urip } \\
\text { Sumoharjo ini harus } \\
\text { dipertahankan sesuai eksisting } \\
\text { yang ada.Karena memiliki Nilai } \\
\text { sejarah yang ada di Kawasan. }\end{array}$ \\
\hline 2 & Pecinaan & $\begin{array}{l}\text { Pada UDGL Pecinaan dibuat } \\
\text { tembusan jalan menuju Jalan } \\
\text { Matraman dan ke Kawasan Pasar } \\
\text { Jatinegara.serta penambahan ruang } \\
\text { terbuka hijau }\end{array}$ & $\begin{array}{l}\text { Pencinaan ini akan mengikuti } \\
\text { UDGL yang mana dapat } \\
\text { meningkatkan nilai dari pecinaan } \\
\text { ini. }\end{array}$ \\
\hline No & Lokasi & Keterangan & Rekomendasi \\
\hline 3 & $\begin{array}{c}\text { Pasar } \\
\text { Jatinegara }\end{array}$ & $\begin{array}{l}\text { Pada UDGL Pasar Jatinegara akan } \\
\text { dilakukan perbaikan Jalan dan } \\
\text { tampak bangunan serta PKL yang } \\
\text { ada. }\end{array}$ & $\begin{array}{l}\text { Pasar Jatinegara ini akan } \\
\text { mengikuti UDGL agar } \\
\text { memberikan yang kenyaman } \\
\text { bagi para pengunjung yang } \\
\text { datang ke pasar ini. }\end{array}$ \\
\hline 4 & $\begin{array}{l}\text { Pasar } \\
\text { Unggas dan } \\
\text { Ikan Hias }\end{array}$ & $\begin{array}{l}\text { Pada UDGL pasar Unggas dan Ikan } \\
\text { Hias ini tidak ada di dalamnya }\end{array}$ & $\begin{array}{l}\text { Pasar Unggas dan ikan hias ini } \\
\text { akan dipertahankan dengan } \\
\text { memberikan lahan yang layak } \\
\text { bagi para penjual pasar ini }\end{array}$ \\
\hline 5 & $\begin{array}{l}\text { Pasar } \\
\text { Jembatan } \\
\text { Hitam }\end{array}$ & $\begin{array}{l}\text { Pada UDGL Pasar Jembatan Hitam } \\
\text { tidak ada di dalamnya. }\end{array}$ & $\begin{array}{l}\text { Pasar Jembatan Hitam ini harus } \\
\text { di Pertahankan dengan } \\
\text { memberikan lapak bagi para } \\
\text { pedagang pasar loak Jembata } \\
\text { Hitam }\end{array}$ \\
\hline 6 & $\begin{array}{l}\text { Gedung Eks } \\
\text { Kodim/ } \\
\text { Museum } \\
\text { Benyamin } \\
\text { Sueb }\end{array}$ & $\begin{array}{l}\text { Pada UDGL bangunan ini merupakan } \\
\text { bangunan Komersial Campuran, } \\
\text { namun pada eksistingnya } \\
\text { merupakan sebuah Museum } \\
\text { Benyamin Sueb yang dijadikan } \\
\text { sebagai pusat kebudayaan Betawi di } \\
\text { Jakarta timur }\end{array}$ & $\begin{array}{l}\text { Gedung Eks Kodim/ Museum } \\
\text { Benyamin Sueb harus } \\
\text { dipertahankan karena } \\
\text { merupakan salah satu Tempat } \\
\text { yang dijadikan Pusat } \\
\text { Kebudayaan Betawi. }\end{array}$ \\
\hline
\end{tabular}

Sumber: Penulis, 2019

\section{Analisis Kebutuhan Ruang}

Penataan Kawasan Segitiga Jatinegara dibagi menjadi 3 zona, yaitu :

a. Zona A, memiliki luas lahan $17,04 \mathrm{Ha}$.ini merupakan pusat kegiatan yang ada di Kawasan Segitiga Jatinegara karena terdapat pintu masuk utama bagi para wisatawan dari luar kota Jakarta yaitu Stasiun Jatinegara, adapun JGC (Jakarta Gems Center) yang merupakan Centra Batu Akik di Jakarta, dan Museum Benyamin Sueb yang merupakan Pusat Keburdayaan Betawi. 
b. Zona B, Memiliki Luar sebesar 10,39 Ha. Pada zona ini terdapat beberapa kegiatan seperti Penginapan, Kantor Polisi, Pusat Kesehatan, Pasar Ikan Hias dan Unggas, CityPlaza Jatinegara, daerah pecinaan dan Komplek Jendral Urip Sumoharjo.

c. Zona C, memiliki luas sebesar 3,07 $\mathrm{Ha}$. Pada zona ini merupakan zona yang diperuntukan untuk wilayah Pasar Jatinegara.seperti Kios-kios berdagang, Tempat Parkir, dan Jatinegara Trade Center.

\section{Rencana Penataan}

Tabel 4. Rencana Penataan

\begin{tabular}{|c|c|}
\hline Rencana & Arahan \\
\hline $\begin{array}{l}\text { 1. Membuat sebuah Ikon Wisata } \\
\text { Jakarta Timur untuk membentuk } \\
\text { sebuah image pada Kawasan } \\
\text { Jatinegara }\end{array}$ & $\begin{array}{l}\text { Mempertahankan nilai sejarah yang ada di Kawasan Segitiga } \\
\text { Jatinegara yang merupakan ciri khas dari kawasan. Dengan } \\
\text { melakukan revitalisasi bangunan-bangunan tua yang sudah } \\
\text { usang atau tua }\end{array}$ \\
\hline $\begin{array}{l}\text { 2. Mengingkatkan fungsi Kawasan } \\
\text { Segitiga Jatinegara sebagai Ikon } \\
\text { Wisata Jakarta Timur dari } \\
\text { potensi-potensi yang ada. }\end{array}$ & $\begin{array}{l}\text { Meningkatkan sarana dan prasarana yang ada di Kawasan } \\
\text { Segitiga Jatinegara seperti perbaikan jalan, penggunaan Share } \\
\text { Surface, penambahan Steert furniture,dan penambahan } \\
\text { sarana penunjang pengunjung. }\end{array}$ \\
\hline $\begin{array}{l}\text { 3. Melakukan penataan kawasan } \\
\text { yang akan dijadikan sebagai } \\
\text { salah satu destinasi wisata di } \\
\text { Jakarta Timur. }\end{array}$ & $\begin{array}{l}\text { Melaksanakan penataan kawasan segitiga jatinegara sesuai } \\
\text { dengan peraturan pemerintah yang ada dan menyesuaikan } \\
\text { dengan pembanding yang seusai dengan penataan Kawasan } \\
\text { Segitiga Jatinegara. }\end{array}$ \\
\hline $\begin{array}{l}\text { 4. Melakukan Penataan PKL di } \\
\text { Kawasan Segitiga Jatinegara }\end{array}$ & $\begin{array}{l}\text { Memberikan lahan yang layak bagi para pedagang kaki lima } \\
\text { yang ada di dalam Kawasan Segitiga Jatinegara. Agar } \\
\text { meningkatkan kenyamanan bagi para pedagang kaki maupun } \\
\text { pengunjung Kawasan ini. }\end{array}$ \\
\hline $\begin{array}{l}\text { 5. Perbaikan bangunan-bangunan } \\
\text { Tua }\end{array}$ & $\begin{array}{l}\text { Melakukan revitalisasi bangunan, dengan merenovasi dan } \\
\text { mengecat ulang bangunan agar lebih menarik dengan } \\
\text { mempertahankan vasat dari bangunan. }\end{array}$ \\
\hline $\begin{array}{l}\text { 6. Menambah fasilitas yang } \\
\text { mendukung Kawasan wisata. }\end{array}$ & $\begin{array}{l}\text { Menambah beberapa hal seperti furniture street, sentra } \\
\text { kuliner, dan penambahan signage yang memberikan } \\
\text { kemudahan orientasi Kawasan. }\end{array}$ \\
\hline
\end{tabular}

Sumber: Penulis, 2019

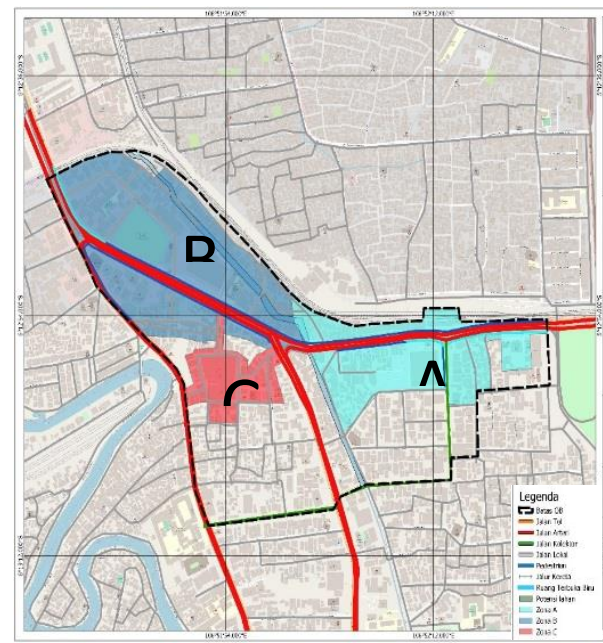

Gambar 2. Masterplan Kawasan Segitiga Jatinegara Sumber: Penulis, 2019 


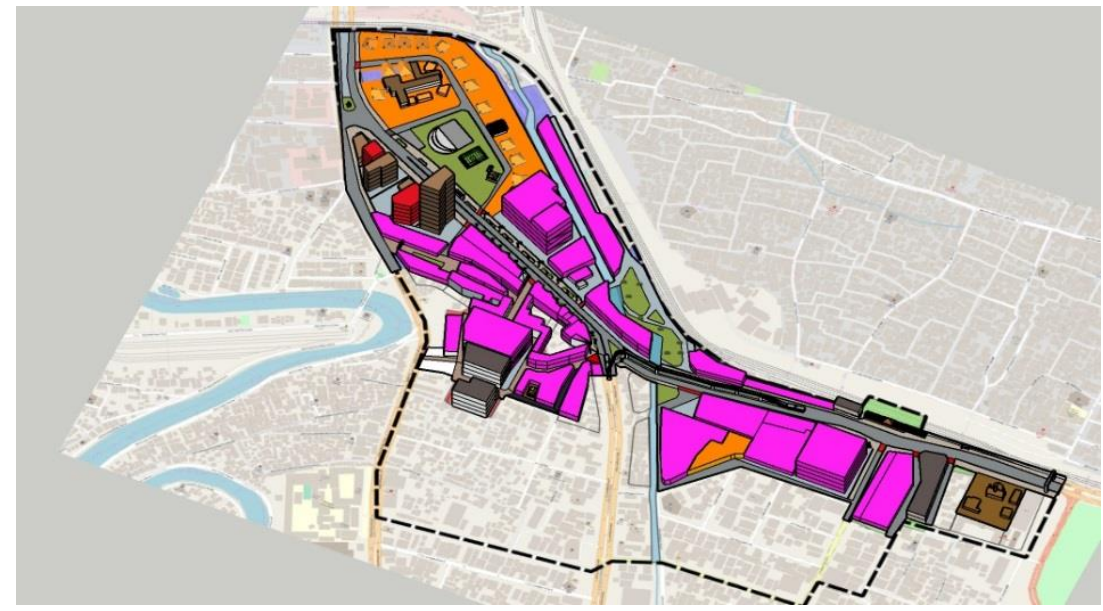

Gambar 3. Sketchup Masterplan Kawasan Segitiga Jatinegara Sumber: Penulis, 2019

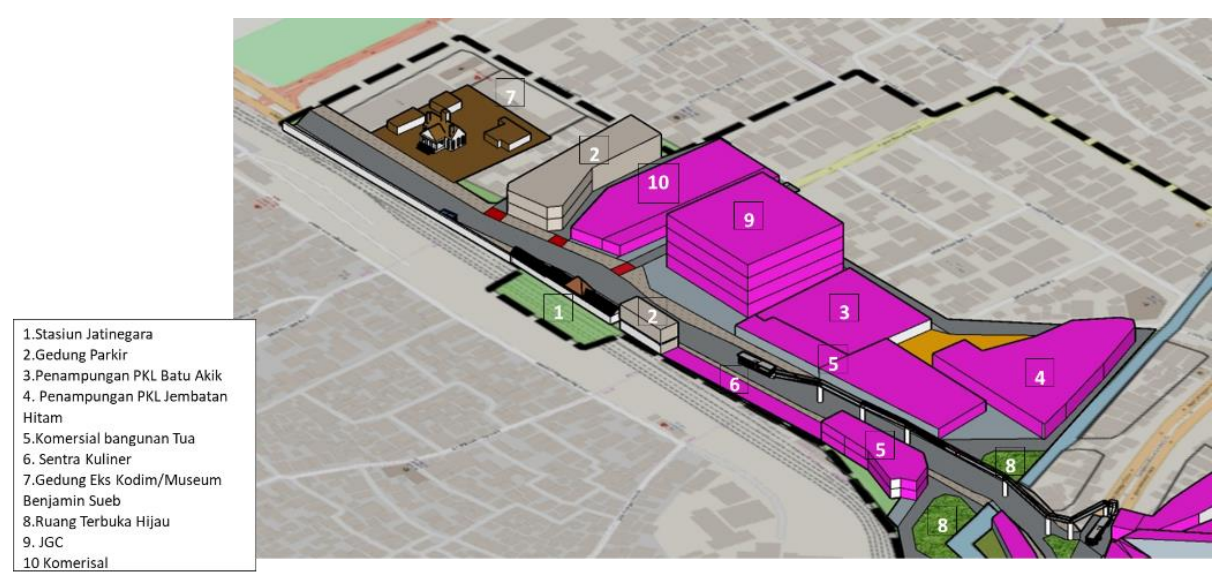

Gambar 4. Masterplan Kawasan Segitiga Jatinegara Zona A Sumber: Penulis, 2019

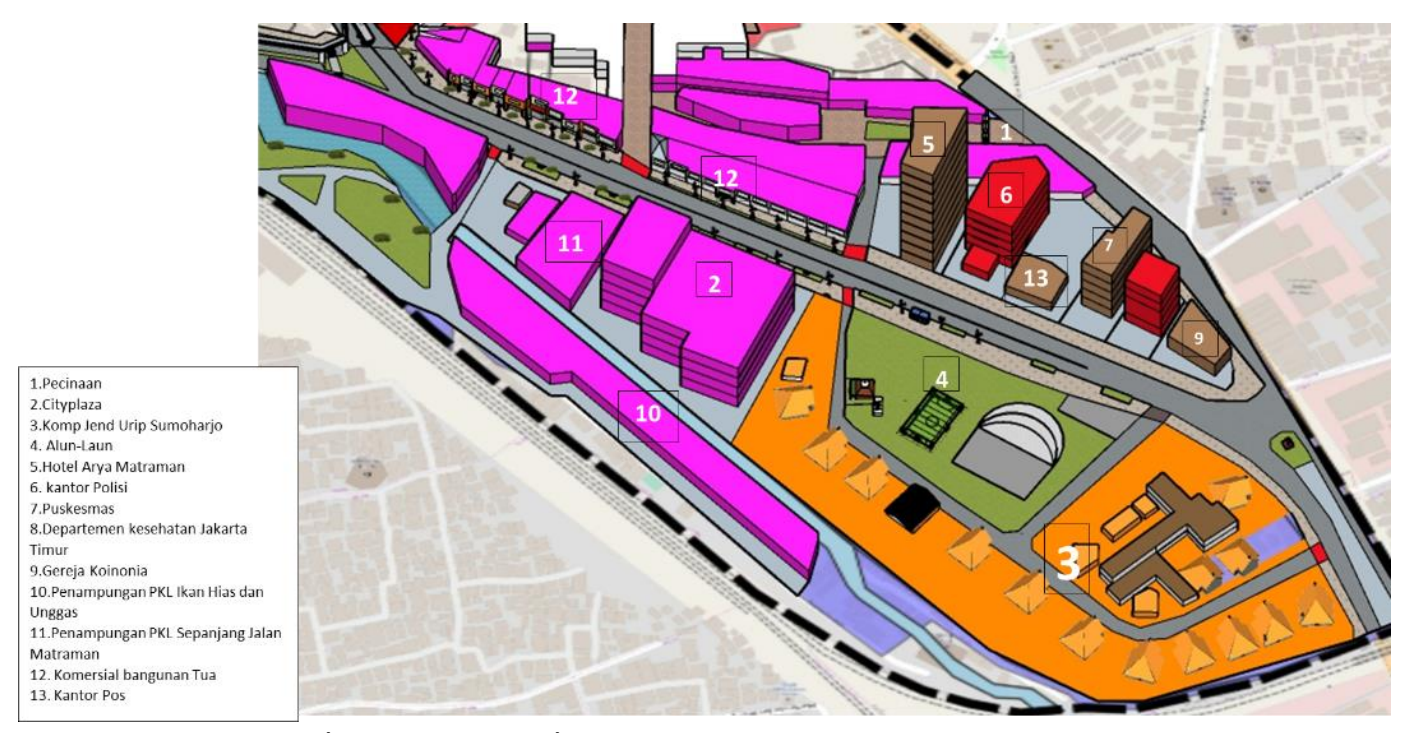

Gambar 5. Masterplan Kawasan Segitiga Jatinegara Zona B

Sumber: Penulis, 2019 


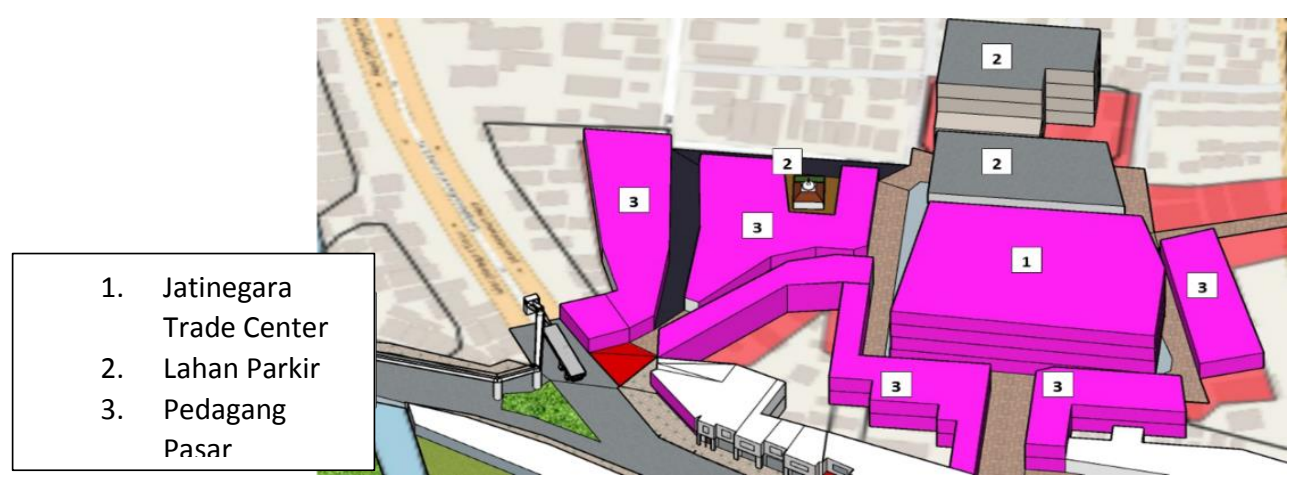

Gambar 6. Masterplan Kawasan Segitiga Jatinegara Zona C

Sumber: Penulis, 2019

\section{Kesimpulan dan Saran \\ Kesimpulan}

Dari penelitian yang telah dilakukan diatas didapatkan kesimpulan sebagai berikut:

a. Kawasan segitiga Jatinegara ini berdasarkan analisis kebijakan yang dijabarkan oleh penulis didapatkan potensi dari Kawasan Segitiga Jatinegara yaitu Kawasan shopping street dengan mempertahakan bangunan bangunan konservasi sebagai Ikon di Jakarta Timur dan juga terdapat Pusat Kebudayaan Betawi di Museum Benyamin Sueb.

b. Berdasarkan analisis Tapak dan Analisis Lokasi Kawasan Segitiga Jatinegara didapat sejumlah masalah seperti Kurangnya Ruang terbuka Hijau, kurangnya lahan Parkir, banyak bangunan tua yang tidak terawatt, dan masih banyaknya PKL yang berjualan di pinggir jalan. Selain potensi dari Kawasan yang harus yang harus dipertahankan

c. Berdasarkan analisis Ikon Kota didapatkan beberapa tempat yang bisa dijadikan sebagai Ikon Kawasan Segitiga Jatinegara seperti bangunan Stasiun Jatinegara, Pasar Jatinegara, Gereja Koinonia, Trotoar, serta Gedung Eks Kodim. Semua berdasarkan hasil Kriteria Image dari Kevin Lynch dan kriteria bangunan Ikon

d. Berdasarkan hasil Analisis nilai sejarah didapatkan bahwa bangunan bersejarah yang memiliki nilai tertinggi ialah Stasiun Jatinegara dan Gereja Koinonia

e. Dari analisis kebutuhan ruang didapatkan pembagian zona di Kawasan Segitiga Jatinegara ini. Zona ini terbagi atas 3 Zona yaitu Zona A sebagai pusat kegiatan dan Zona B dan C sebagai sub Zona dan Pusat pedagangan.

f. Konsep Shopping Street dengan bangunan konservasi ini merupakan salah satu perwujudan dari UDGL (Urban Desaign Guideline) Kawasan Segitiga Jatinegara yang merupakan salah satu Kawasan Strategis Ekonomi di DKI Jakarta.

\section{Saran}

Dari penelitian yang telah dilakukan diatas, didapatkan beberapa saran untuk kawasan Segitiga Jatinegara, yaitu:

a. Perlu adanya peraturan yang jelas terkait dengan pembangunan Kawasan Segitiga Jatinegara agar dapat menjadikan Kawasan yang ini sesuai dengan konsep yang di tentukan.

b. Perlunya penindakan yang tegas terhadap PKL di Kawasan Segiiga Jatinegara agar dapat mengurangi pelanggaran yang terjadi yang mengakibatkan masalah bagi Kawasan Segitiga Jatinegara

c. Pemerintah harus bekerja sama dengan swasta dalam mengembangkan Kawasan Segitiga Jatinegara dengan konsep Shopping Street dengan bangunan Konservasi, agar dapat merealisasikan kawasan ini. 


\section{REFERENSI}

Bappeda Provinsi DKI Jakarta. Rencana Pembangunan Jangka Menengah Daerah (RPJMD) Provinsi DKI Jakarta Tahun 2017-2022.

Bugis Warta, "Icon Kota Adalah Simbol Eksistensi Budaya". 26 November 2016. www.bugiswarta.com/2016/11/icon-kota-adalah-simbol-eksistensi.html

Cahyadi, R. dan Gunawan, J. (2009). Pariwisata Pusaka Masa Depan Bagi Kita, Alam dan Warisan Budaya Bersama. Jakarta. Unesco \& Program Vokasi Pariwisata Universitas Indonesia

Maryani, E. (1991). Pengantar Geografi Pariwisata, Bandung: Jurusan Pendidikan Geografi FPIPS IKIP

International Union of Official Travel Organization (IUOTO)

Kodyat, H. (1983). Sejarah Pariwisata dan Perkembangnannya di Indonesia. PT Gramedia Pustaka Utama. Jakarta

Lynch, K. (1960). The Image Of The City, The MIT Press, Cambridge

Neufert, E. (1993). Data Arsitek Edisi Kedua Jilid 1. Jakarta: Erlangga.

Oka A. Y. (1992). Pengantar Ilmu Pariwisata, Jakarta : Pradnya Paramita.

Pemerintah DKI Jakarta. (2010). Laporan Akhir UDGL Kawasan Sentra Primer Timur. Jakarta

Pemerintah Provinsi DKI Jakarta (2015). RTRW Kota/Kabupaten Administrasi Provinsi DKI Jakarta 2030.

Pendit, N. S. (2003). Ilmu Pariwisata Sebuah Pengantar Perdana. Jakarta: PT Pradnya Paramita

Peraturan Daerah No 1 Tahun 2014. Tentang Rencana Detail Tata Ruang Dan Peraturan Zonasi 2030.

Republik Indonesia. (1992). Undang-Undang Nomor 5 Tahun 1992 Tentang Benda Cagar Budaya. Presiden Republik Indonesia. Jakarta.

Republik Indonesia. (2007). Undang-Undang Nomor 26 Tahun 2007 Tentang Penataan ruang. Presiden Republik Indonesia. Jakarta.

Republik Indonesia. (2009). Undang-Undang Nomor 10 Tahun 2009 Tentang Kepariwisataan. Presiden Republik Indonesia. Jakarta.

Republik Indonesia. (2018). Peraturan Menteri Pariwisata dan Ekonomi Kreatif No. 3 Tahun 2018 tentang Petunjuk Operasional Pengelolaan Dana Alokasi Fisik Bidang Pariwisata. Jakarta: Menteri Pariwisata dan Ekonomi Kreatif.

Smith, M and Skousen, F. (1989), Intermediate Accounting Edisi Kesembilan Jilid Satu, Jakarta: Erlangga.

Suyitno. (2001). Perencanaan Wisata. Yogyakarta: Kanisius. 